\title{
Phototransformation of halogenoaromatic derivatives in aqueous solution
}

\author{
P. Boule, ${ }^{1}$ K. Othmen, ${ }^{1}$ C. Richard, ${ }^{1}$ B. Szczepanik, ${ }^{2}$ \\ and G. Grabner ${ }^{3}$ \\ ${ }^{1}$ Laboratoire de Photochimie Moléculaire et Macromoléculaire (UMR CNRS 6505) \\ Université Blaise Pascal (Clermont-Ferrand) F-63177 Aubière Cedex, France \\ ${ }^{2}$ Institute of Chemistry, Pedagogical University, Checińska 5, Pl-25-020 Kielce, Poland \\ ${ }^{3}$ Institut für Theoretische Chemie und Strahlenchemie, Universität Wien, \\ Althanstrasse 14, A-1090 Wien Austria
}

\begin{abstract}
The photochemical behaviour of monohalogeno-phenols and -anilines is highly dependent on the position of the halogen on the ring, but most often it is not significantly influenced by the nature of the halogen $(\mathrm{Cl}, \mathrm{Br}, \mathrm{F})$. Photohydrolysis is the main reaction observed with 3-halogenated and it is almost specific. With 2-halogenated, photohydrolysis and photocontraction of the ring compete, the latter being very efficient with 2-halogeno-phenolates.

The photochemical behaviour of 4-halogeno-phenols and -anilines is more complex. It depends on both concentration and oxygenation. It was rationalized when it was experimentally proved by laser flash photolysis that the first step is the formation of a carbene (in the cationic form in the case of 4-halogenoaniline). $p$-Benzoquinone is the product of photooxidation of 4-halogenophenols, whereas the photooxidation of 4-chloroaniline leads to 4-amino- $4^{\prime}$-chlorodiphenylamine.

Chlorohydroquinone behaves differently, the formation of the main photoproducts involving a radical mechanism.

With dihalogenoanilines photohydrolysis is initially almost quantitative whatever the position of halogen atom on the ring. It occurs more easily in meta than in ortho position and in ortho than in para position. In the case of 2,4- and 2,6-dichloroanilines aminophenoxazones are formed as secondary photoproducts. This reaction involves the intermediate formation of $o$-benzoquinone monoimine.

Several halogenoaromatic herbicides were also studied (bromoxynil, chlorpropham, propanil, diuron, linuron, chlorbromuron, MCPA). The most frequent reaction is photohydrolysis. However some other reactions such as photoreduction and photo-demethoxylation were observed. In some cases a wavelength effect was observed particularly with MCPA and halogenophenylureas.
\end{abstract}

\section{INTRODUCTION}

Chloroaromatic derivatives are pollutants commonly found in aquatic media since many of them are used in the field of pesticides. In the present work a special attention is focused on the mechanism of the photochemical transformation of chlorophenols and chloroanilines since the formation of these compounds may result from the degradation of pesticides. They generally absorb in UVB region and their photodegradation may play a significant role in their elimination from natural waters. In some cases the kinetic and analytical studies in continuous irradiation were completed by the identification of short-lived intermediates by means of laser flash photolysis. The photochemical behaviour of several pesticides is also presented.

\section{MATERIALS AND METHODS}

Reactants were of highest grade available and used as received.

Several devices were used for irradiation of solutions. Low pressure mercury lamps (germicide lamps) were used for irradiation at $254 \mathrm{~nm}$. Quantum yields were measured in monochromatic light using either high pressure mercury lamp (200 W) equipped with a monochromator Bausch \& Lomb, or a xenon lamp
$(1600 \mathrm{~W})$ with a monochromator Schoeffel. Potassium ferrioxalate was used as the actinometer. For isolation of photoproducts, solutions were most often irradiated with Duke Sun lamps GL 20 emitting in the range 275$350 \mathrm{~nm}$ (maximum at $313 \mathrm{~nm}$ ). This emission may be cut off at $\lambda>290 \mathrm{~nm}$ using a Pyrex filter. In some cases, (to study wavelength effects), solutions were irradiated with "black light" lamps Mazda MAW 125 (main line at $365 \mathrm{~nm}$, minor emissions at 313 and $334 \mathrm{~nm}$ ), or in sunlight.

Laser flash photolysis studies were carried out with a frequency-quadrupled Nd:YAG laser (Quanta-Ray DCRI, pulse duration $7 \mathrm{~ns}, \lambda_{\mathrm{exc}}=266 \mathrm{~nm}$ ).

Solutions were analysed by HPLC on column $\mathrm{C}_{18} 5 \mu \mathrm{m}$ $250 \mathrm{~mm} \times 4.6 \mathrm{~mm}$ using UV detection (photodiode array detector).

Isolated photoproducts were identified by ${ }^{1} \mathrm{H}$ NMR (Bruker AC 400) and mass spectrometry (various mass spectrometers were used).

\section{RESULTS AND DISCUSSION}

3.1. UV spectra. The pKas of monohalogenophenols (chloro, fluoro, bromo) lie within the range 8-10. In natural waters they are mainly in the neutral form, and absorb at wavelengths shorter than $300 \mathrm{~nm}$. However it is noteworthy that anionic forms absorb at longer wave- 
lengths, up to about $320 \mathrm{~nm}$, and their excitation has to be taken into account $[1,2]$.

Mono- and dichloroanilines generally absorb at wavelengths shorter than $330 \mathrm{~nm}$, the maximum of absorption being located between 280 and $300 \mathrm{~nm}$. They are protonated at low $\mathrm{pH}$ (pKa in the range 2.5-4.0 for monochloroanilines, lower than 2.2 for dichlorinated anilines), but cationic forms are almost transparent in the UV range and their excitation may be neglected $[3,4,5]$. The case of 2,5-dichloroaniline is given as an example in Figure 1.

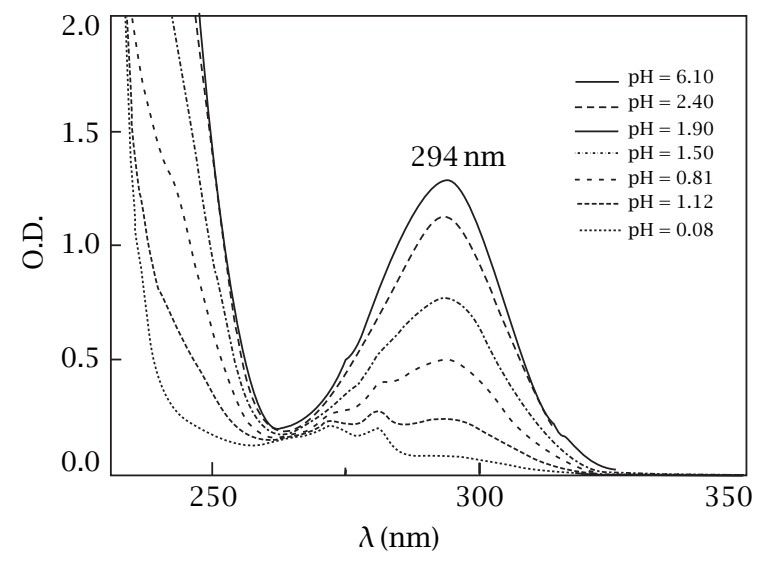

Figure 1. UV spectrum of 2,5-dichloroaniline at various $\mathrm{pH}$.

Most of aromatic pesticides reported in the present paper absorb very little at wavelengths longer than $300 \mathrm{~nm}$, except bromoxynil which is a dibromo derivative and absorbs up to about $330 \mathrm{~nm}$ [6]. However, this weak absorption of solar radiations is often sufficient to obtain the photodegradation in a few weeks out-doors in summer time.

3.2. Phototransformation of monohalogenophenols. The analytical and kinetic study of the photochemical behaviour of monohalogenophenols was the subject of many publications, particularly in the case of 4-chlorophenol.

The irradiation of 3-halogenophenols leads to the formation of resorcinol with a high chemical yield $(>80 \%)$ $[1,7,8]$ whatever the $\mathrm{pH}$, even at $\mathrm{pH}$ as low as 0.5 . It does not depend on the presence of oxygen $[1,8]$. The quantum yield was evaluated at 0.09 with the neutral form of 3 -chlorophenol and at about 0.15 with 3-fluorophenol. The reaction can be explained by a heterolytic mechanism involving a molecule of water (photohydrolysis).
The same type of reaction is observed with 2halogenophenol in neutral form, but only as a minor pathway. The main reaction is the formation of cyclopentadiene carboxylic acids. The latter is almost quantitative with the anionic form. The quantum yield of photolysis was evaluated at 0.30 with 2chlorophenolate [1]. It is about 10-times smaller with the neutral form. The mechanism of this reaction was recently elucidated when the intermediate formation of a ketene was observed in laser flash photolysis (Figure 2). The transient was assigned to a ketene by comparison with the transient obtained by photolysis of diazocyclopentadiene in CO low temperature matrix [9].

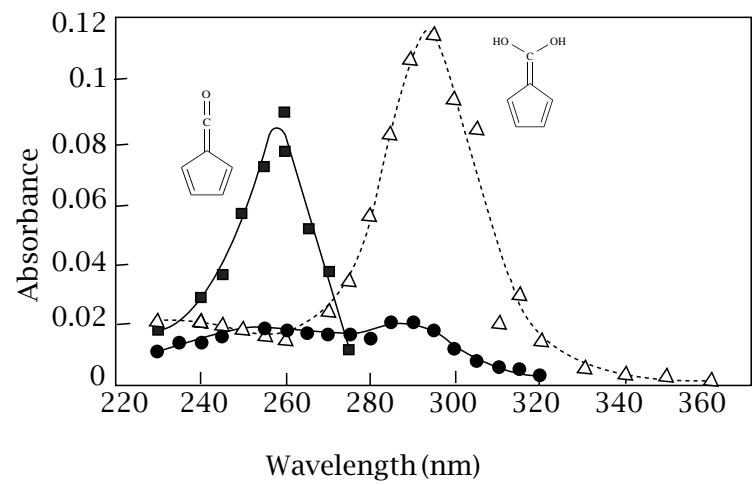

Figure 2. Transient spectra obtained on irradiating an aqueous solution of 2-chlorophenol $5 \times 10^{-4} \mathrm{M}$ $\left(120 \mathrm{~mJ} \cdot \mathrm{cm}^{-2}\right)[10]$

- neutral solution, absorbance extrapolated at pulse end $\triangle$ neutral solution, absorbance $8 \mu \mathrm{s}$ after pulse end •pH 2 absorbance $20 \mu$ s after pulse end.

The ketene adds water and rearranges into cyclopentadiene carboxylic acids (Scheme 1).

The phototransformation of 4-halogenophenols is more complex. 4-Chlorophenol was the subject of many publications $[1,8,11,12,13,14,15,16,17]$. Its photochemical behaviour depends on both concentration and oxygenation. The quantum yield is high (0.6-1.0) and depends on the concentration. Benzoquinone is the main photoproduct in the presence of oxygen. Hydroquinone is only formed in deoxygenated solution. The formation of 5-chloro-2, $4^{\prime}$ dihydroxybiphenyl increases with increasing concentration. At high conversion extent the reaction becomes very complex, polyhydroxybiphenyls and polycyclic oligomers were identified. This reactivity was

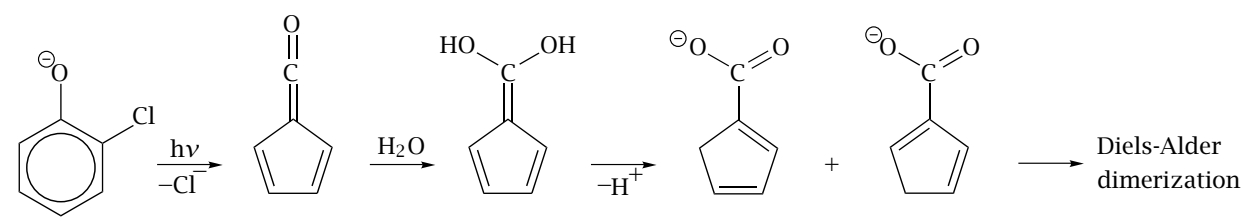


rationalized when it was pointed out that the first step of the reaction is the formation of a carbene (4-oxocyclohexa-2,5-dienylidene) [15, 16]. It is characterized by a two-band absorption with maxima at 370 and $384 \mathrm{~nm}$. According to the experimental conditions this carbene reacts with oxygen (formation of benzoquinone), with water leading to hydroquinone or with 4-chlorophenol (formation of 5-chloro-2,4'dihydroxybiphenyl). In the presence of a reductant it can also lead to the formation of phenol or dihydroxybiphenyl. 4-Bromo- and 4-fluorophenols have similar behaviour.

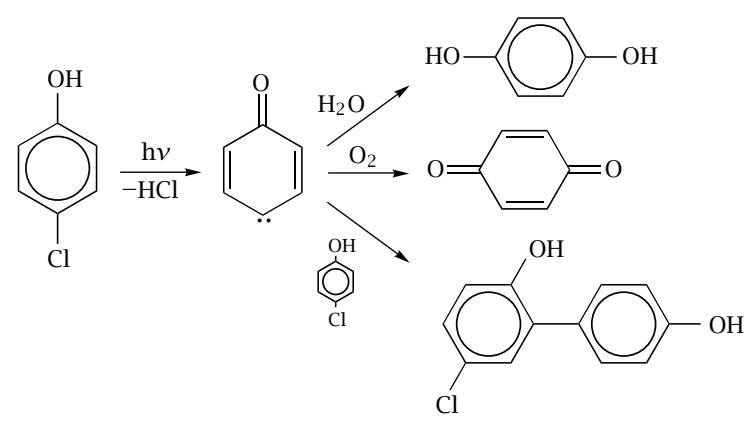

Scheme 2

The photochemical behaviour of 4-chlororesorcinol is related to both 2-chloro- and 4-chlorophenol [18]. In basic solution the photocontraction of the ring is almost quantitative whereas in acidic medium it competes with the formation of 1, 2, 4-trihydroxybenzene and polyhydroxybiphenyls (Scheme 3).

Some dichlorophenols were also investigated [19]. 3,5- and 3,4-dichlorophenols react as 3-chlorophenol whereas 2,4-dichloro isomer reacts as 2-chlorophenol.

In contrast chlorohydroquinone behaves differently [20]. In solution $10^{-3} \mathrm{M}$ it is almost quantitatively transformed into an equimolecular mixture of hydroquinone and chlorobenzoquinone. This photodisproportionation results from a radical mechanism since semiquinone and probably chlorosemiquinone radicals appear in the solution (Scheme 4).

Benzoquinone appears as a minor photoproduct, but its formation is favoured by dilution.

3.3. Phototransformation of monohalogenoanilines Monohalogenophenols and monohalogenoanilines have similar photochemical behaviour except in the case of 4-halogenoanilines in the presence of oxygen. The photolysis of halogenoanilines results from the excitation of neutral forms, since cationic forms absorb very little in the UV range and their photodegradation in sunlight can be neglected.

With 3-halogenoanilines the photochemical conversion into 3-aminophenol is initially almost quantitative [3]. No influence of oxygen was observed and the quantum yield of the reaction is slightly higher with 3 fluoroaniline (0.15) than with 3-chloroaniline (0.12). A heterolytic mechanism of photohydrolysis is assumed. In a second stage resorcinol is formed among with several unidentified products (Scheme 5).<smiles>CC(C)(C)C1=CCC(C(=O)O)=C1C(=O)[O-]</smiles>

Scheme 3<smiles>O=C1C=CC(=O)C(Cl)=C1</smiles> 
<smiles>Nc1cccc(Cl)c1</smiles>

\section{Scheme 5}

The irradiation of 2-halogenoanilines leads to a mixture of 2-aminophenol (photohydrolysis) and 1,3cyclopentadiene-1-carbonitrile [4] (photocontraction of the ring). A minor formation of aniline was observed in the absence of oxygen.<smiles>N#CC1=C[C+](c2ccccc2N)C=C1</smiles>

Scheme 6

The quantum yield is higher with fluoro derivative (0.10) than with chloro- (0.02) and bromoderivative (0.04) that is consistent with a heterolytic mechanism.

As for 4-chlorophenol, the photochemical behaviour of 4-halogenoanilines is much more complex and depends on both concentration and oxygenation. The quantum yield of disappearance is in the range 0.6-0.9 with 4-chloroaniline according to the conditions, a little higher with 4-fluoroaniline and lower with 4-bromoaniline. In the absence of oxygen the main photoproducts are 4-aminophenol, 2,4'-diamino5-halogenobiphenyl and one of its isomers. A minor formation of aniline was also observed. Aniline and 4aminophenol are not formed in the presence of oxygen, but new photoproducts appear. The main one was identified as 4 -amino- $4^{\prime}$-chlorodiphenylamine. Most probably 4-amino- $4^{\prime}$-hydroxydiphenylamine is also formed.

This complex reactivity is explained by the initial formation of a carbene (cationic form of it) pointed out by Szczepanik and Grabner by means of laser flash photolysis [21] (Figure 3).

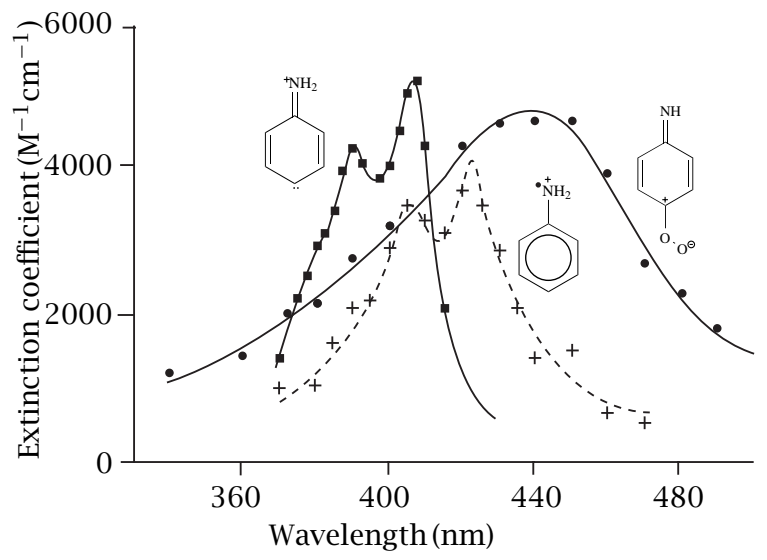

Figure 3. Transient spectra obtained on irradiating on aqueous solution of 4-chloroaniline $\left(\lambda_{\mathrm{exc}}=266 \mathrm{~nm}\right)$ [21].
The photochemical behaviour of 4-halogenoanilines (4-XA) can be summarized on Scheme 7

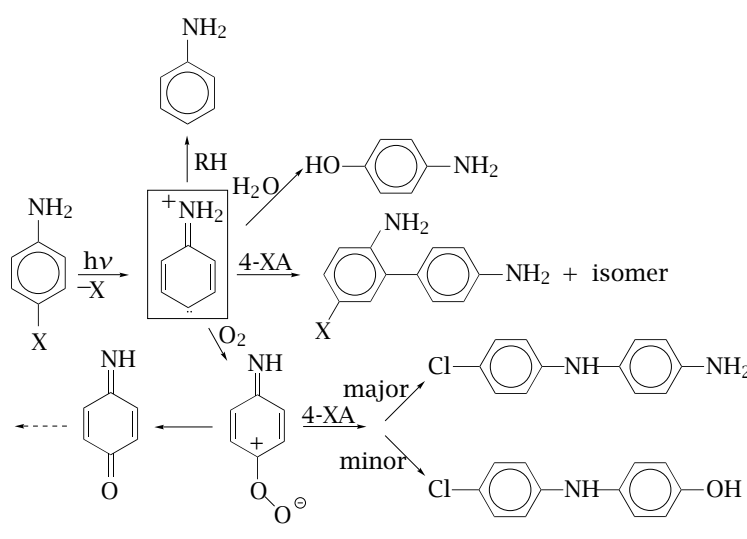

Scheme 7

3.4. Dichloroanilines All dichloroanilines were investigated [5] except 3,4-DCA which was previously studied by Miller et al. [22]. The main initial photoreaction is photohydrolysis. It leads to aminochlorophenol, the quantum yield ranging between 0.01 and 0.06 . It was observed that the quantum yield is notably higher with 2,4- and 2,6-difluoroanilines that with corresponding DCAs. The half-life of DCA in sunlight (latitude $46^{\circ} \mathrm{N}$, altitude $400 \mathrm{~m}$, July) is about 3 hours for 3,4-DCA, about 8 hours for 2,3- and several days for 2,6-DCA. With 2,3-, 2,5- and 3,5-DCA the main photoproduct results from the reaction in meta.

With 2,4- and 2,6-DCA the main initial photoproduct is a substituted 2-aminophenol, but it does not accumulate and it is phototransformed into a 2aminophenoxazin-3-ones. This reaction involves the intermediate formation of $o$-benzoquinone monoimine. In the case of 2,4-DCA the formation of 2-amino-7chlorophenoxazin-3-one can be explained by the final elimination of $\mathrm{HCl}$ (Scheme 8).

The reaction is a little more complex with 2,6DCA. Actually the excitation of 2-amino-3-chlorophenol leads to the formation of several aminophenoxazones. The formation of 2-amino-1, 9-dichlorophenoxazin-3one needs the presence of oxygen and can be explained by the addition of 3-chloro-1,2-benzoquinone monoimine on 2-amino-3-chlorophenol, followed by an oxidation. However the formation of 2-amino1-chlorophenoxazin-3-one and 2-aminophenoxazin-3one in the absence of oxygen let assume that the formation of $o$-benzoquinone monoimine results from the elimination of $\mathrm{HCl}$, the final oxidation being attributed to $o$-benzoquinone monoimine.

3.5. Chloroaromatic Herbicides Several halogenoaromatic herbicides were irradiated in aqueous solution (Scheme 9).

The reaction most commonly observed is photo- 

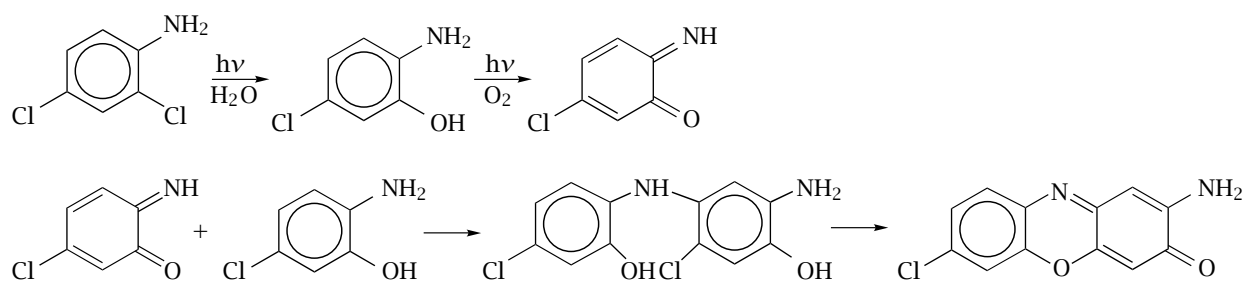

Scheme 8<smiles>N#Cc1cc(Br)c(O)c(Br)c1</smiles><smiles>COC(Nc1cccc(Cl)c1)OC(C)C</smiles><smiles>CCCCCCCC(=O)Nc1ccc(Cl)c(Cl)c1</smiles><smiles>Cc1cc(Cl)ccc1OCC(=O)O</smiles>

Bromoxynil Chlorpropham Propanil MCPA<smiles>CN(C)C(=O)Nc1ccc(Cl)c(Cl)c1</smiles><smiles>CON(C)C(=O)Nc1ccc(Cl)c(Cl)c1</smiles>

Linuron

Scheme 9

hydrolysis. It is the major pathway with Bromoxynil [6], Chlorpropham [3], Propanil and Diuron [23], the three other herbicides show a more complex behaviour. With Propanil irradiated at short wavelengths photohydrolysis mainly occurs in meta position, as it is with dichloroanilines, but the proportion of para hydroxylation increase with increasing irradiation wavelength.

In the case of Diuron photohydrolysis in meta position corresponds to about $90 \%$ of the transformation when solutions are irradiated at $254 \mathrm{~nm}$, but the para hydroxylated compound [3-(3-chloro-4- hydroxyphenyl]-1,1-dimethylurea is the main photoproduct obtained when Diuron is irradiated in "black light" (main line at $365 \mathrm{~nm}$, a low percentage of energy at 313 and $334 \mathrm{~nm}$ ). Such a wavelength effect was also observed with Linuron and Chlorbromuron. It may be related to the presence of $\mathrm{CO}-\mathrm{NH}$ group, since it does exist with 3,4-dichlorophenol.

In the case of Linuron and Chlorbromuron other reactions compete with photohydrolysis. With both compounds the elimination of the methoxy group mainly occurs when solutions are irradiated at $254 \mathrm{~nm}$ but it plays a minor role in sunlight. It is explained by a Norrish-type II reaction. The formation of formaldehyde has been experimentally proved [24].

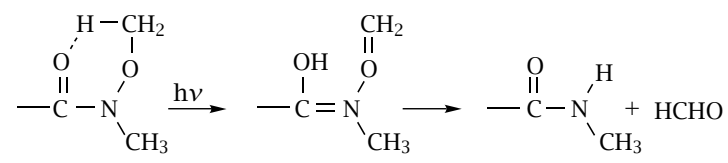

It was reported by Soley et al. [25] that the photoproducts initially formed in the photodegradation of MCPA (4-chloro-2-methylphenoxyacetic acid) irradiated with a mercury lamp HPK 125 or in simulated sunlight in the presence of a photosensitizer, are 4-chloro2-methylphenol and 4-chloro-2-methylphenyl formate. Actually a wavelength effect was observed by Zertal et al. [26]. Upon irradiation at $254 \mathrm{~nm}$ the photohydrolysis accounts for about $85 \%$ of the transformation, a photoFries rearrangement being also observed, whereas in sunlight 4-chloro-2-methylphenol is the main photoproduct. When solutions are irradiated in the range 290-350 nm (UV-B) photohydrolysis occurs but the formation of 4-chloro-2-methylphenol is not negligible (Scheme 10).<smiles>Cc1cc(Cl)ccc1OCC(=O)OCC(=O)OCC(=O)OCC(=O)O</smiles>

Scheme 10 


\section{CONCLUSIONS}

Monohalogenophenols and monohalogenoanilines have similar photochemical behaviours, but 4halogeno-phenols and -anilines react differently in the presence of oxygen. It is highly dependent on the position of the halogen on the ring, but it is not significantly influenced by the nature of the halogen $(\mathrm{Cl}, \mathrm{F}, \mathrm{Br})$.

Photohydrolysis is almost specific with 3-halogenophenols and -anilines. It results from a heterolytic mechanism more efficient with fluoro than with chloro derivatives.

With 2-halogenated compounds photohydrolysis competes with the photocontraction of the ring, the latter being much more efficient with 2halogenophenolate than with the neutral form. The intermediate formation of a ketene was observed in laser flash photolysis.

Para-halogenated compounds have a more complex photochemical behaviour due to the intermediate formation of a carbene characterized by laser flash photolysis.

In contrast with monochlorophenols the phototransformation of chlorohydroquinone involves a radical mechanism.

Photohydrolysis is the main initial reaction of dichloroanilines, but with 2,4- and 2,6-DCAs aminophenoxazones as formed as secondary photoproducts.

Photohydrolysis is also observed with many halogenated pesticides, but some other reactions were observed and in some case the photochemical behaviour depends on the irradiation wavelength, particularly with MCPA and dihalogenophenylureas.

\section{ACKNOWLEDGEMENTS}

The authors are grateful to Centre National de la Recherche Scientifique (CNRS) and the French Ministère des Affaires Etrangères for a large part of financial support and to Rhône-Poulenc Agro for providing high grade Diuron.

\section{REFERENCES}

[1] P. Boule, C. Guyon, and J. Lemaire, Chemosphere 11 (1982), 1179.

[2] K. David-Oudjehani and P. Boule, New J. Chem. 19 (1995), 199.

[3] B. David, M. Lhote, V. Faure, and P. Boule, Water Res. 32 (1998), 2451.

[4] K. Othmen and P. Boule, Bull. Environ. Contam. Toxicol. 59 (1997), 924.
[5] K. Othmen and P. Boule, J. Photochem. Photobiol. A: Chem. 121 (1999), 161.

[6] F. Machado, L. Collin, and P. Boule, Pestic. Sci. 45 (1995), 107.

[7] E. Lipczynska-Kochany, Chemosphere 24 (1992), 911.

[8] P. Boule, C. Guyon, and J. Lemaire, Toxicol. Environ. Chem. 7 (1984), 97.

[9] M. S. Baird, I. R. Dunkin, N. Hacker, M. Poliakoff, and J. J. Turner, J. Am. Chem. Soc. 103 (1981), 5190.

[10] C. Richard and G. Grabner, Poster presented at XVth IUPAC Symposium on Photochemistry Prague, 1994.

[11] K. Omura and T. Matsuura, Tetrahedron 27 (1971), 3101.

[12] E. Lipczynska-Kochany and J. R. Bolton, J. Photochem. Photobiol. A: Chem. 58 (1991), 315.

[13] E. Lipcynska-Kochany, J. Kochany, and J. R. Bolton, J. Photochem. Photobiol. A: Chem. 62 (1991), 229.

[14] K. Oudjehani and P. Boule, J. Photochem. Photobiol. A: Chem. 68 (1992), 363.

[15] G. Grabner, C. Richard, and G. Köhler, J. Am. Chem. Soc. 116 (1994), 11470.

[16] A. P. Durand, R. G. Brown, D. Worrall, and F. Wilkinson, J. Photochem. Photobiol. A: Chem. 96 (1996), 35.

[17] H. D. Burrows, L. Ernestova, T. J. Kemp, Y. I. Skurlatov, A. P. Purmal, and A. N. Yermakov, Prog. React. Kinet. 23 (1998), 145.

[18] P. Krajnik, C. Richard, and G. Grabner, Poster presented at "Gordon Research Conference on Physical Organic Chemistry”-Plymouth (USA), 1995.

[19] P. Boule, C. Guyon, and J. Lemaire, Chemosphere 13 (1984), 603.

[20] A. Rossi, A. Tournebize, and P. Boule, J. Photochem. Photobiol. A: Chem. 85 (1995), 213.

[21] B. Szczepanik and G. Grabner, Poster presented at XVIIIth International Conference on Photochemistry Warsaw (Poland), 1997.

[22] G. C. Miller, M. J. Miille, D. G. Crosby, S. Sontum, and R. G. Zepp, Tetrahedron 35 (1979), 1797.

[23] J. Jirkovský, V. Faure, and P. Boule, Pestic. Sci. 50 (1997), 42.

[24] V. Faure and P. Boule, Pestic. Sci. 51 (1997), 413.

[25] J. Soley, M. Vicente, P. J. Clapés, and S. Espulgas, Ind. Eng. Chem. Prod. Res. Dev. 25 (1986), 645.

[26] A. Zertal, T. Sehili, and P. Boule, Z. Phys. Chem., in press. 


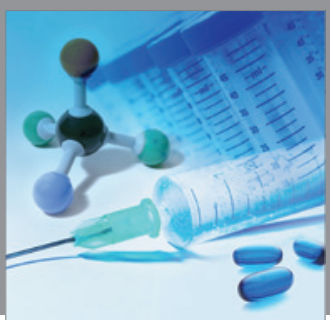

International Journal of

Medicinal Chemistry

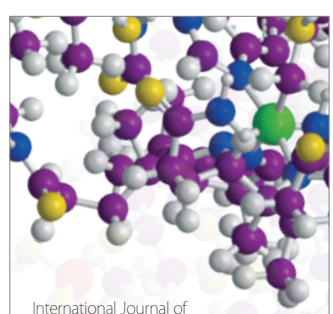

Carbohydrate Chemistry

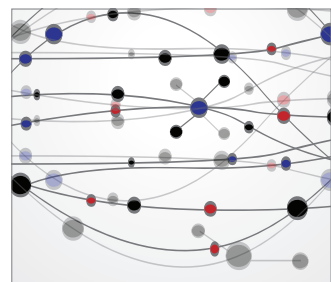

The Scientific World Journal
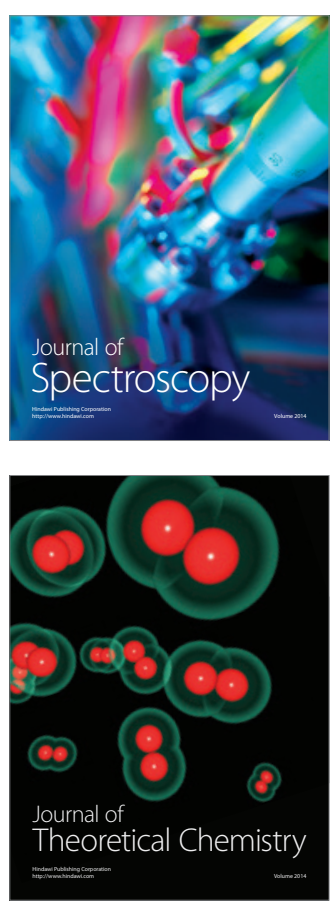
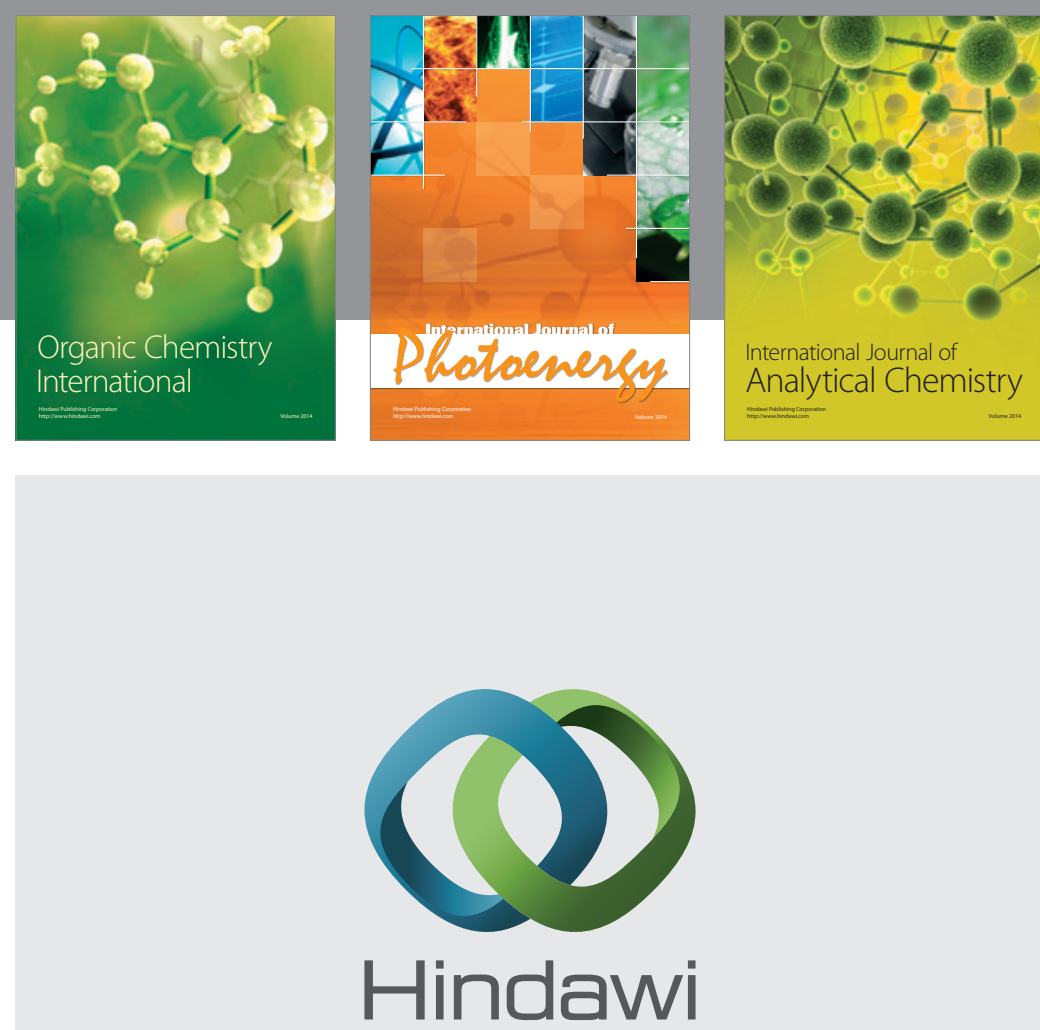

Submit your manuscripts at

http://www.hindawi.com
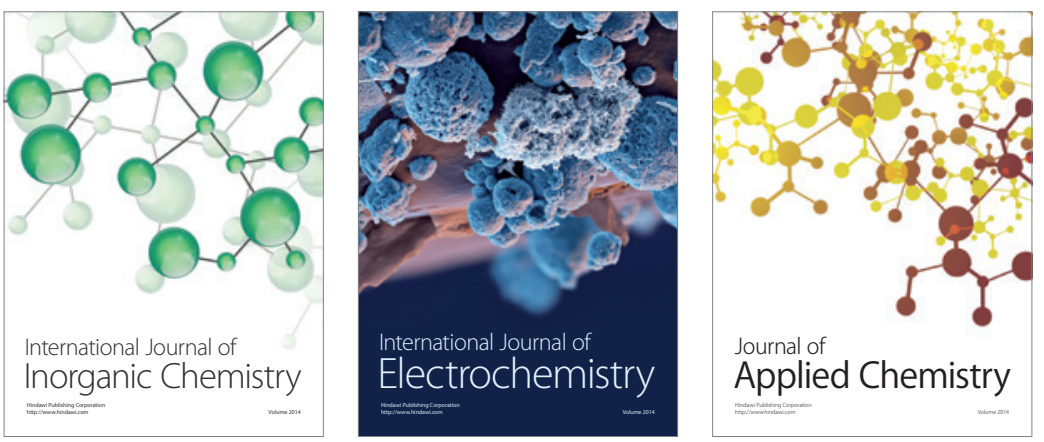

Journal of

Applied Chemistry
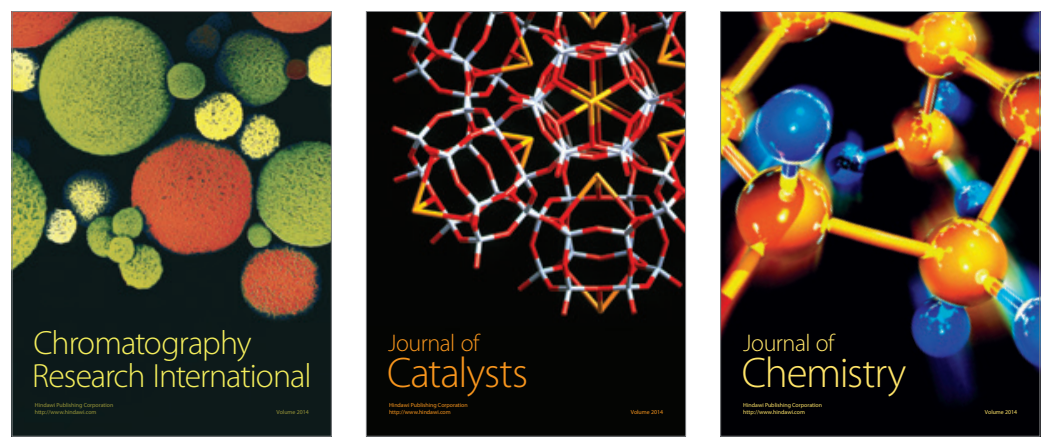
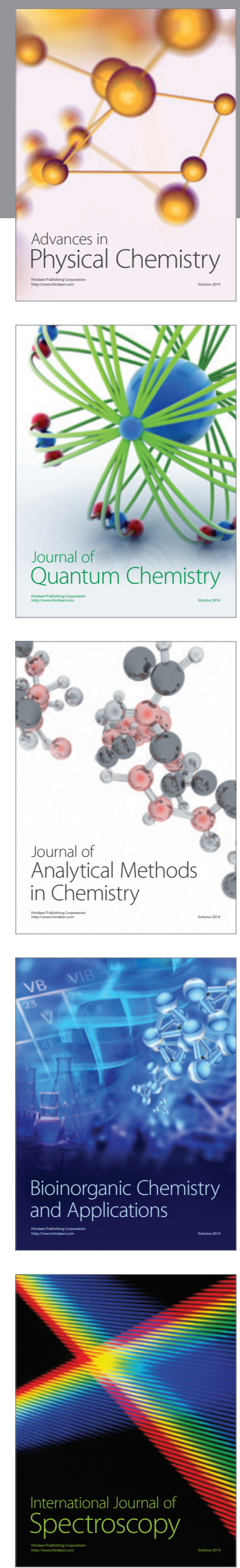